\title{
Comparison of the Effects of Smoking and Smokeless Tobacco "Maras Powder" Use on Pulmonary Function, Electrocardiogram and Other Parameters
}

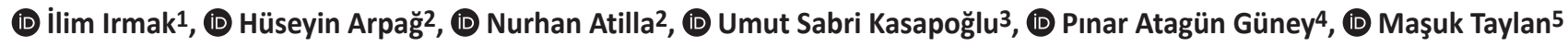 \\ ${ }_{1}^{1}$ Göksun State Hospital, Clinic of Chest Diseases, Kahramanmaraş, Turkey \\ ${ }^{2}$ Kahramanmaraş Sütçü Imam University Faculty of Medicine, Department of Pulmonary Medicine, Kahramanmaraş, Turkey \\ 3 Marmara University Istanbul Pendik Training and Research Hospital, Unit of Pulmonology and Intensive Care, Istanbul, Turkey \\ 4istanbul Süreyyapaşa Chest Diseases and Thoracic Surgery Training and Research Hospital, Clinic of Chest Diseases, Istanbul, Turkey \\ ${ }^{5}$ Dicle University Faculty of Medicine, Department of Pulmonary Medicine, Diyarbakır, Turkey
}

\section{Abstract}

Objective: Through the years, tobacco has been used in many ways. While the most common way of consumption is through smoking cigarettes, smokeless use by chewing or nasal snuffing are also quite common. Smokeless tobacco, also named "Maras powder", is generally used as a substitute to reduce or quit smoking. The effects of smokeless tobacco use on the immune system, respiratory system and cardiovascular system have been extensively researched. In our study, we aimed to investigate the effects of Maras powder on the respiratory, electrocardiogram (ECG) findings and biochemical methods.

Methods: One hundred and forty-nine cases were included and the cases were classified into the following four groups: only using Maras powder; using Maras powder and smoking; only smoking and control group neither smoking nor using Maras powder. Physical examination findings, ECG findings, results of pulmonary function tests, results of biochemical analysis including complete blood count and lipid profile of all participants were recorded on admission.

Results: The risk of mouth sores was 7.9 times higher in the Maras powder group due to direct contact to the oral mucosa. There is a relationship between the daily use frequency of smokeless tobacco and the development of oral wounds, but the total period of use or the duration in mouth was not related to this situation. The ECG findings of both the smoking and Maras powder consuming group was found to be significantly higher than the control group.

Conclusion: The smokeless tobacco use, which is considered as an alternative way of quitting smoking, does not have adverse effects on respiratory functions. However, it is an important risk factor for many life-threatening health conditions such as ECG abnormalities and occurrence of oral lesions. Social awareness must be created for smokeless tobacco use in order to fight this habitual threat to public health.

Keywords: Tobacco smokeless, Maras powder, tobacco

\section{INTRODUCTION}

Over the years, tobacco has been used in many ways. While the most common form of consumption is through smoking cigarettes, smokeless use by chewing or nasal snuffing are also quite common $(1,2)$.

The use of "smokeless tobacco" is popular in Eastern Anatolia and South-Eastern Anatolia regions of Turkey, especially within and around the cities of Kahramanmaraș and Gaziantep. Two studies conducted in Turkey reported the smokeless tobacco use rate as $4.0 \%$ and $16.8 \%$, respectively $(3,4)$. Smokeless tobacco, also named "Maras powder," has generally been used as a substitute to reduce or quit smoking. Maras powder is made from leaves of a plant called Nicotiana rustica Linn. The leaves of this tobacco plant are dried and powdered, followed by mixing with ashes of vine, oak, or walnut sticks at a rate of $1 / 2$ or $1 / 3$ and mildly moisturized with some water. The final product refined through this process is used orally. The refined mixture is wrapped in cigarette paper or directly applied between lower lip or cheek mucosa and jaw. It is kept in the mouth for 5 to 10 minutes or sometimes for 1 or 2 hours until it is disposed. This process 
is repeated several times according to the addiction level of the individual. Interestingly, the addict can even sleep with the tobacco in his/her mouth to curb the cravings of nicotine (5-7). The effects of smokeless tobacco use on the immune system, respiratory system and cardiovascular system have been extensively researched. Studies suggest that Maras powder has no effect on respiratory function, since it is not inhaled (8). On the other hand, the use of Maras powder was found to be associated with the development of atherosclerosis due to its ability to reduce nitric oxide production and increase oxidative stress $(9,10)$. Thus, it has been concluded that use of Maras powder has negative effects on the cardiovascular system (11). Additionally, it has been suggested that Maras powder affects chronic inflammatory modifications at organ and systemic level due to its nicotine content and tobacco-specific nitrosamine (12).

As shown in our study, local people use Maras powder in order to prevent the harmful effects of smoking on respiratory functions. Therefore, in addition to the detrimental effects of Maras powder on respiratory functions, electrocardiogram (ECG) abnormalities, oral lesions and changes in routine biochemical blood counts have been also demonstrated by our results. In addition, our study was conducted in the region where the Maras powder is used heavily. More patients were included in this study than in previous studies. With this aspect, this study will contribute to the literature of Maras powder use in Turkey.

\section{METHODS}

This retrospectively designed study included patients referred to the Department of Pulmonary Medicine at Dr. Sureyya Adanalı Göksun State Hospital and Kahramanmaraş Sütçü İmam University Faculty of Medicine between June 2013 and August 2014. Exclusion criteria were the presence of accompanying systemic diseases such as Chronic Obstructive Pulmonary disease (COPD), malignancies, hypertension, heart failure, ischemic heart disease, diabetes mellitus, liver and kidney failure, and/ or current medical treatment. One hundred and forty-nine men were included and were classified into the following four groups: only using Maras powder $(n=38)$; using Maras powder and smoking $(n=41)$; only smoking $(n=33)$; and control group of neither smoking nor using Maras powder $(n=37)$. Frequency of use, duration of use and method of use (direct contact of powder with oral mucosa or using wrapped in cigarette paper) were noted for the participants using Maras powder. Duration of smoking, packs per year and current smoking status were noted with the participants' coal or biomass exposure and additional medical conditions. Systolic and diastolic blood pressure, physical examination findings (sores in mouth, gum abnormalities, abnormal respiratory sounds), ECG findings (presence of arrhythmias), results of pulmonary function tests (FEV1, FVC, FEV1/FVC measurements), results of routine biochemical analysis including complete blood count and lipid profile of all participants were recorded upon admission (Tables 1, 2). The study was approved by the Local Ethics Committee and was in accordance with the Declaration of Helsinki (24.11.2014/181).

\section{Statistical Analysis}

SPSS version 18.0 was used for statistical analysis. A $p$ value of less than 0.05 , with confidence interval of 95\%, was considered statistically significant. Kolmogorov-Smirnov test was used to determine the consistency of numeric variables with normal distribution. Parametric tests were used in the analysis of data consistent with normal distribution. One-way ANOVA test was used to compare the numerical variables between the groups. Multivariate analysis was processed to determine if the statistically significant data at ANOVA test were originating from group variables or other factors such as age and gender. Chisquare analysis was used to compare abnormal ECG findings between the case groups. Binary logistic regression test was used to identify the data associated with mouth sores. ROC analysis was used to determine cut-off values, specificity and sensitivity values and statistically significance of numeric variables of factors that could be associated with development of sores such as duration of Maras powder, use (in years), daily amount, duration held in mouth, and amount of smoking (as pack per year).

\section{RESULTS}

One hundred forty nine cases were included and $91.3 \%$ of them were male. The mean age of the participants was $43.7 \pm 16.3$ years. The rate of Maras powder users and smokers were $53.0 \%$ and $49.7 \%$, respectively. Maras powder users (91.1\%) and smokers (54.1\%) were currently using these products. Among the Maras powder users, $84.8 \%$ were using it wrapped in paper (indirect contact) and the frequency of daily use was $13.8 \pm 11.4$ days, mean duration of use was $13.4 \pm 12.1$ years, and mean duration held in mouth was $17.0 \pm 14.9$ minutes. Mean duration of use was 18.8 \pm 15.6 packs per year for the smokers. Dust or smoke exposure and coal or biomass exposure cases were $40.3 \%$ and $79.2 \%$, respectively (Table 1). Eight point one percent of the cases had mouth lesions and $14.8 \%$ had abnormal ECG findings (arrhythmia, etc.). The demographic distribution of complete blood count and biochemical analysis of the cases are shown in Table 2. The binary logistic regression test, which 
was used to identify causative parameters for mouth lesions, found the method and number of daily use of Maras powder as statistically significant variables $(p=0.026$ and $p=0.035$, respectively). The risk for mouth sores was 7.9 times higher in the Maras powder group due to direct contact with the oral mucosa. For each additional daily session of Maras powder use, risk for mouth sores increased by 1.055 times (Table 3). Among the numerical parameters that could be associated with mouth sores, ROC analysis revealed statistically insignificant findings for the duration of Maras powder use in years and duration held in mouth ( $p=0.566$ and $p=0.243$, respectively). However, the amount of daily use was found to be statistically significant $(p=0.035$, area under curve $=0.692)$. The cut-off value for the amount of daily use was 17.5. The sensitivity for mouth sores was $66.7 \%$ and specificity was $74.6 \%$ (Figure 1). When the groups were compared with chi-square analysis for abnormal ECG findings, the control group had no ECG abnormality. In contrast, $15.8 \%$ of only Maras powder users, $18.2 \%$ of only smokers, and $24.4 \%$ of both Maras powder users and smokers had statistically significant increases in ECG abnormalities $(p=0.021)$ (Figure 2). Diastolic blood pressure, hemoglobin ( $\mathrm{Hb})$, leukocytes and cholesterol levels were found to be statistically and significantly different as determined by One-way ANOVA test, which compared physical examination findings, results of pulmonary function test, complete blood count, lipid profile, and numerical parameters of the other biochemical variables (Table 3). Tukey's

\begin{tabular}{|c|c|c|c|c|c|c|c|c|c|c|c|}
\hline & & \multicolumn{2}{|c|}{ Control } & \multicolumn{2}{|c|}{$\begin{array}{l}\text { Maras } \\
\text { powder }\end{array}$} & \multicolumn{2}{|c|}{ Tobacco } & \multicolumn{2}{|c|}{\begin{tabular}{|l|} 
Maras \\
powder + tobacco
\end{tabular}} & \multicolumn{2}{|c|}{ Total } \\
\hline & & \multicolumn{2}{|c|}{$(n=37)$} & \multicolumn{2}{|c|}{$(n=38)$} & \multicolumn{2}{|c|}{$(n=33)$} & \multicolumn{2}{|c|}{$(n=41)$} & \multicolumn{2}{|c|}{$(n=149)$} \\
\hline & & $\mathrm{n}$ & $\%$ & $\mathbf{n}$ & $\%$ & $n$ & $\%$ & $n$ & $\%$ & $\mathbf{n}$ & $\%$ \\
\hline \multirow[t]{2}{*}{ Gender } & Female & 9 & 24.3 & 2 & 5.3 & 2 & 6.1 & 0 & 0.0 & 13 & 8.7 \\
\hline & Male & 28 & 75.7 & 36 & 94.7 & 31 & 93.9 & 41 & 100.0 & 136 & 91.3 \\
\hline \multirow[t]{2}{*}{ Comorbidity } & No & 37 & 100.0 & 38 & 100.0 & 33 & 100.0 & 41 & 100.0 & 149 & 100.0 \\
\hline & Yes & 0 & 0.0 & 0 & 0.0 & 0 & 0.0 & 0 & 0.0 & 0 & 0.0 \\
\hline \multirow[t]{2}{*}{ Dust exposition } & No & 24 & 64.9 & 18 & 47.4 & 25 & 75.8 & 22 & 53.7 & 89 & 59.7 \\
\hline & Yes & 13 & 35.1 & 20 & 52.6 & 8 & 24.2 & 19 & 46.3 & 60 & 40.3 \\
\hline \multirow[t]{2}{*}{ Biomass exposition } & No & 12 & 32.4 & 4 & 10.5 & 14 & 42.4 & 1 & 2.4 & 31 & 20.8 \\
\hline & Yes & 25 & 67.6 & 34 & 89.5 & 19 & 57.6 & 40 & 97.6 & 118 & 79.2 \\
\hline \multirow[t]{2}{*}{ Tobacco smoking status } & Non smoker & 37 & 100.0 & 38 & 100.0 & 0 & 0.0 & 0 & 0.0 & 75 & 50.3 \\
\hline & Smoker & 0 & 0.0 & 0 & 0.0 & 33 & 100.0 & 41 & 100.0 & 74 & 49.7 \\
\hline \multirow[t]{2}{*}{ Still tobacco smoker } & No & 0 & 0.0 & 0 & 0.0 & 5 & 15.2 & 29 & 70.7 & 34 & 45.9 \\
\hline & Yes & 0 & 0.0 & 0 & 0.0 & 28 & 84.8 & 12 & 29.3 & 40 & 54.1 \\
\hline \multirow[t]{2}{*}{ Maras powder status } & No & 37 & 100.0 & 0 & 0.0 & 33 & 100.0 & 0 & 0.0 & 70 & 47.0 \\
\hline & Yes & 0 & 0.0 & 38 & 100.0 & 0 & 0.0 & 41 & 100.0 & 79 & 53.0 \\
\hline \multirow[t]{2}{*}{ Still using Maras powder } & No & 0 & 0.0 & 4 & 10.5 & 0 & 0.0 & 3 & 7.3 & 7 & 8.9 \\
\hline & Yes & 0 & 0.0 & 34 & 89.5 & 0 & 0.0 & 38 & 92.7 & 72 & 91.1 \\
\hline \multirow[t]{2}{*}{ Direct mouth contact } & No & 0 & 0.0 & 0 & 0.0 & 0 & 0.0 & 38 & 92.7 & 38 & 92.7 \\
\hline & Yes & 0 & 0.0 & 0 & 0.0 & 0 & 0.0 & 3 & 7.3 & 3 & 7.3 \\
\hline \multirow[t]{2}{*}{ Mouth lesion } & No & 37 & 100.0 & 27 & 71.1 & 33 & 100.0 & 39 & 95.1 & 136 & 91.3 \\
\hline & Yes & 0 & 0.0 & 11 & 28.9 & 0 & 0.0 & 2 & 4.9 & 13 & 8.7 \\
\hline \multirow[t]{2}{*}{ Arrhythmia } & No & 37 & 100.0 & 32 & 84.2 & 27 & 81.8 & 31 & 75.6 & 127 & 85.2 \\
\hline & Yes & 0 & 0.0 & 6 & 15.8 & 6 & 18.2 & 10 & 24.9 & 22 & 14.8 \\
\hline \multirow[t]{2}{*}{ Operation history } & No & 34 & 91.9 & 31 & 81.6 & 27 & 81.8 & 27 & 65.9 & 119 & 79.9 \\
\hline & Yes & 3 & 8.1 & 7 & 18.4 & 6 & 18.2 & 14 & 34.1 & 30 & 20.1 \\
\hline \multirow{3}{*}{$\begin{array}{l}\text { Complication during general } \\
\text { anesthesia }\end{array}$} & No & 3 & 100.0 & 5 & 71.4 & 5 & 83.3 & 8 & 57.1 & 21 & 70.0 \\
\hline & Yes & 0 & 0.0 & 1 & 14.3 & 1 & 16.7 & 2 & 14.3 & 4 & 13.3 \\
\hline & Unknown & 0 & 0.0 & 1 & 14.3 & 0 & 0.0 & 4 & 28.6 & 5 & 16.7 \\
\hline
\end{tabular}




\begin{tabular}{|c|c|c|c|c|c|c|c|c|c|c|c|c|c|c|c|}
\hline \multicolumn{16}{|l|}{ Case groups } \\
\hline & \multicolumn{2}{|c|}{ Control $(n=37)$} & \multicolumn{2}{|c|}{$\begin{array}{l}\text { Maras powder } \\
(\mathrm{n}=38)\end{array}$} & \multicolumn{2}{|c|}{ Tobacco $(n=33)$} & \multicolumn{2}{|c|}{$\begin{array}{l}\text { Maras powder + } \\
\text { tobacco }(n=41)\end{array}$} & \multicolumn{7}{|l|}{$p$ values } \\
\hline & Mean & SD & Mean & SD & Mean & SD & Mean & SD & $p$ values & p1 & $\mathrm{p} 2$ & p3 & p4 & p5 & p6 \\
\hline Age & 40.6 & 14.3 & 45.6 & 21.0 & 40.3 & 12.9 & 47.5 & 15.3 & 0.140 & & & & & & \\
\hline $\begin{array}{l}\text { Tobacco smoking } \\
\text { duration (year) }\end{array}$ & & & & & 19.2 & 12.1 & 16.2 & 10.2 & 0.253 & & & & & & \\
\hline $\begin{array}{l}\text { Tobacco smoking } \\
\text { amount (packet/ } \\
\text { year) }\end{array}$ & & & & & 19.1 & 13.3 & 18.8 & 17.4 & 0.934 & & & & & & \\
\hline $\begin{array}{l}\text { Maras powder } \\
\text { amount (number/ } \\
\text { day) }\end{array}$ & & & 14.6 & 13.0 & & & 13.2 & 10.0 & 0.612 & & & & & & \\
\hline $\begin{array}{l}\text { Maras powder } \\
\text { using duration } \\
\text { (year) }\end{array}$ & & & 14.9 & 12.9 & & & 12.1 & 11.4 & 0.301 & & & & & & \\
\hline $\begin{array}{l}\text { Retention time in } \\
\text { mouth (min) }\end{array}$ & & & 16.2 & 11.0 & & & 17.9 & 17.9 & 0.617 & & & & & & \\
\hline Heart rate & 88.1 & 16.4 & 85.9 & 16.9 & 86.5 & 17.1 & 83.0 & 14.7 & 0.567 & & & & & & \\
\hline Systolic BP & 116.5 & 15.8 & 118.2 & 11.8 & 126.4 & 18.8 & 117.9 & 20.3 & 0.730 & & & & & & \\
\hline Diastolic BP & 73.0 & 9.4 & 74.5 & 8.6 & 79.4 & 12.0 & 77.1 & 8.1 & 0.030 & 0.904 & 0.028 & 0.233 & 0.136 & 0.620 & 0.725 \\
\hline $\mathrm{SPO}^{2}$ & 97.2 & 1.5 & 97.2 & 1.1 & 97.2 & 1.2 & 96.9 & 1.7 & 0.790 & & & & & & \\
\hline FVC (mL) & 3.459 .2 & 1.092.1 & 3.507 .1 & 893.8 & 3.703 .3 & 813.0 & 3.344 .5 & 904.7 & 0.450 & & & & & & \\
\hline FVC (\%) & 81.5 & 15.9 & & & 82.4 & 12.6 & 77.7 & 16.4 & 0.383 & & & & & & \\
\hline FEV1 (mL) & 3.201 .6 & 946.8 & 3.277 .7 & 821.7 & 3.359 .1 & 801.3 & 3.007 .1 & 846.2 & 0.160 & & & & & & \\
\hline FEV1 (\%) & 91.4 & 15.7 & 93.3 & 14.5 & 90.2 & 14.3 & 85.5 & 16.5 & 0.346 & & & & & & \\
\hline FEV1/FVC & 93.6 & 7.2 & 93.7 & 6.3 & 90.6 & 7.4 & 89.9 & 8.4 & 0.056 & & & & & & \\
\hline FEF 25-75 (mL) & 4.346 .8 & 1.599 .5 & & & 4.050 .9 & 1.409 .4 & 3.797 .4 & 1.485 .4 & 0.290 & & & & & & \\
\hline FEF 25-75 (\%) & 100.5 & 27.7 & & & 94.0 & 26.4 & 94.4 & 29.6 & 0.540 & & & & & & \\
\hline PEF (mL) & 4.076 .2 & 1.073 .6 & & & 4.361 .5 & 837.3 & 3.719 .2 & 954.6 & 0.022 & & 0.220 & 0.130 & & & 0.004 \\
\hline PEF (\%) & 80.4 & 14.2 & & & 84.6 & 20.7 & 71.9 & 16.4 & 0.008 & & 0.310 & 0.020 & & & 0.005 \\
\hline WBC & 7.367 .3 & 1.750 .2 & \begin{tabular}{|l|l}
7.318 .4 \\
\end{tabular} & 1.921 .5 & 7.450 .6 & 2.308 .3 & 7.249 .5 & 1.930 .1 & 0.018 & 0.440 & 0.570 & 0.567 & 0.032 & 1.000 & 0.034 \\
\hline PLT & 255.702 .7 & 54.074 .0 & 242.342 .1 & 67.008 .4 & 231.727 .3 & 48.957 .4 & 226.780 .5 & 46.842 .6 & 0.110 & & & & & & \\
\hline HB & 13.9 & 1.3 & 14.0 & 1.6 & 14.9 & 1.2 & 14.5 & 1.0 & $<0.001$ & 1.000 & 0.010 & 0.179 & 0.011 & 0.248 & 0.499 \\
\hline NE (\%) & 59.1 & 8.7 & 62.0 & 9.2 & 56.8 & 7.3 & 61.1 & 9.6 & 0.070 & & & & & & \\
\hline E0 (\%) & 2.6 & 2.2 & 2.9 & 4.0 & 2.2 & 1.2 & 3.2 & 4.9 & 0.610 & & & & & & \\
\hline M0 (\%) & 8.1 & 1.8 & 7.9 & 2.8 & 8.9 & 4.2 & 7.2 & 3.5 & 0.150 & & & & & & \\
\hline LY (\%) & 28.7 & 8.6 & 25.7 & 8.5 & 30.1 & 6.1 & 26.9 & 7.4 & 0.090 & & & & & & \\
\hline $\mathrm{BA}(\%)$ & 0.6 & 0.7 & 0.4 & 0.6 & 0.5 & 0.3 & 0.4 & 0.8 & 0.494 & & & & & & \\
\hline Albumin & 4.3 & 0.4 & 4.1 & 0.3 & 4.3 & 0.4 & 4.2 & 0.4 & 0.050 & & & & & & \\
\hline Glucose & 100.4 & 15.2 & 104.0 & 21.0 & 101.2 & 18.3 & 107.7 & 52.7 & 0.740 & & & & & & \\
\hline AST & 21.8 & 10.4 & 22.3 & 7.6 & 19.7 & 6.5 & 19.8 & 6.2 & 0.370 & & & & & & \\
\hline ALT & 20.0 & 10.0 & 18.6 & 6.3 & 21.8 & 13.5 & 20.5 & 13.0 & 0.670 & & & & & & \\
\hline Amylase & 64.0 & 17.2 & 74.2 & 22.3 & 72.0 & 21.2 & \begin{tabular}{|l}
73.7 \\
\end{tabular} & 26.1 & 0.170 & & & & & & \\
\hline Cholesterol & 156.6 & 34.0 & 163.6 & 34.5 & 178.9 & 35.6 & 172.7 & 37.5 & 0.040 & 0.830 & 0.040 & 0.195 & 0.268 & 0.668 & 0.874 \\
\hline HDL & 43.1 & 9.4 & 40.3 & 8.9 & 44.9 & 13.9 & 41.0 & 11.5 & 0.280 & & & & & & \\
\hline LDL & 97.7 & 25.3 & 102.7 & 28.4 & 116.0 & 27.9 & 113.7 & 27.6 & 0.012 & 0.850 & 0.029 & 0.052 & 0.170 & 0.280 & 0.980 \\
\hline
\end{tabular}




\begin{tabular}{|l|l|l|l|l|l|l|l|l|l|l|l|l|l|l|l|}
\hline VLDL & 26.4 & 18.0 & 27.8 & 14.3 & 32.2 & 18.9 & 33.8 & 15.1 & 0.160 & & & & & & \\
\hline TG & 130.5 & 90.4 & 134.8 & 71.7 & 169.8 & 94.4 & 157.0 & 75.3 & 0.150 & & & & & & \\
\hline LDH & 189.4 & 30.2 & 201.8 & 40.7 & 178.3 & 23.4 & 201.1 & 42.6 & 0.018 & 0.430 & 0.560 & 0.460 & 0.032 & 0.990 & 0.034 \\
\hline CK & 183.9 & 182.1 & 182.2 & 182.2 & 144.8 & 85.6 & 111.0 & 50.1 & 0.060 & & & & & & \\
\hline
\end{tabular}

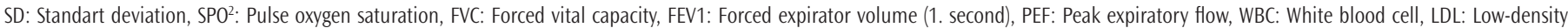

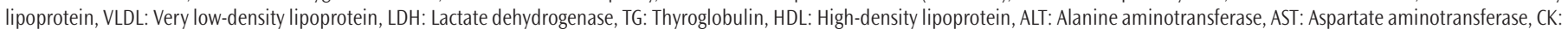
Creatine kinase, HB: Hemoglobin, PLT: Platelets, p: (ANOVA or T test)

significiant value, $\mathrm{p}^{1}$ : Control-tobacco, $\mathrm{p}^{2}$ : control-maras powder, $\mathrm{p}^{3}$ : Control-tobacco plus maras powder, $\mathrm{p}^{4}$ : Tobacco-maras powder, $\mathrm{p}^{5}$ : Tobacco-tobacco plus maras

powder, p6: Maras powder-tobacco plus maras powder sig. values

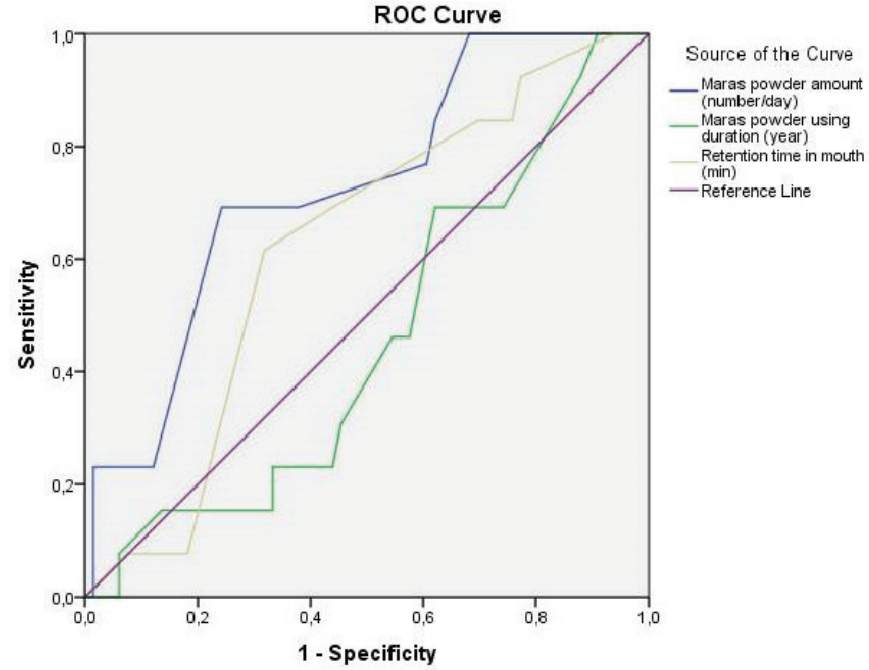

Figure 1. Sensitivity and spesifity of amount of usage, using duration and retention time in mouth for maras powder (ROC curve)

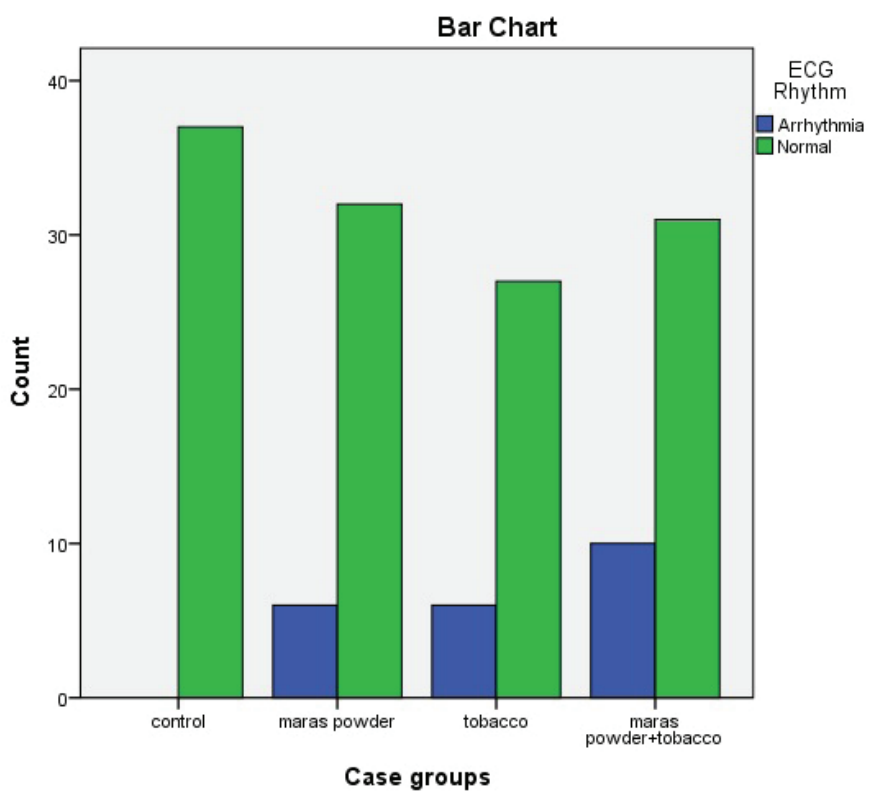

Figure 2. Bar chart of electrocardiogram comparisons for patient groups

ECG: Electrocardiogram

test in ANOVA was processed to determine which subgroups had statistically significant differences. Multivariate analysis was processed to determine whether this statistically significant
Table 3. Factors determining mouth lesion (binary logistic test)

\begin{tabular}{|c|c|c|c|c|c|c|c|c|}
\hline & B & S.E & Wald & $d f$ & p & OR & & $\mathrm{Cl}$ \\
\hline $\begin{array}{l}\text { Direct } \\
\text { mouth } \\
\text { contact } \\
\text { (direct } \\
\text { contact } \\
\text { group) }\end{array}$ & 2.072 & 0.765 & 7.332 & 1 & 0.007 & 7.942 & 0 & \\
\hline $\begin{array}{l}\text { Maras } \\
\text { powder } \\
\text { amount } \\
\text { (number/ } \\
\text { day) }\end{array}$ & 0.054 & 0.026 & 4.431 & 1 & 0.035 & 1.055 & 0.99 & 1.42 \\
\hline Constant & -3.044 & 0.639 & 22.686 & 1 & 0 & 0.048 & & \\
\hline
\end{tabular}

difference originated from the group variables or other factors such as age and gender. We found that none of these parameters actually differed between group variables $(p=0.716)$. Instead, they were determined by age and gender $(p<0.001$ and $p=0.009$, respectively). The same analysis revealed the age factor to be associated with diastolic blood pressure $(p=0.02), \mathrm{Hb}$ $(p<0.001)$ and cholesterol level $(p=0.001)$. Also, the age factor was associated with $\mathrm{Hb}$ level $(p<0.001)$.

\section{DISCUSSION}

Tobacco use is a global problem similar to drug addiction and alcohol abuse. While the developed countries have reduced smoking rates as a government policy, smoking still remains an important health problem for most developing countries. Turkey has come a long way in the fight against tobacco use through the restrictions on tobacco consumption, purchasing of products and the creation of social awareness about the issue. As a tobacco variety, cigarette alternative products such as smokeless tobacco should be carefully evaluated for in order to increase public awareness. Unfortunately, the targeted level of smokeless tobacco use (especially in the Eastern and Southeastern regions of Turkey) has not been reached yet (notice no: 2013/4 published by Kahramanmaraş Governorship, Tobacco Control Council). The 
common belief of "it is less harmful than smoking", cheaper prices, consideration of smokeless tobacco as an alternative method to stop smoking, and its ease of use in "non-smoking" areas are some of the underlying reasons why smokeless tobacco use is rapidly increasing (13-16). Numerous studies have researched the effects of smokeless tobacco on carcinogenesis, oral health, the respiratory system, and the cardiovascular system as well as the immunological, biochemical and hematological parameters. The nicotine content of Nicotiana rustica L. has been reported to be 6-10 times higher than the nicotine content of Nicotiana tabacum used for cigarettes (17). One study revealed that blood nicotine levels were 15 times higher when tobacco was consumed orally, compared to smoking (18). A limiting factor in the evaluation of the results of our study was that we did not measure nicotine levels of participants.

Nicotine and other chemicals in tobacco are responsible for the harmful effects on multiple organs, including the respiratory system. The effects of smokeless tobacco on these same systems have been documented to be equal or greater $(19,20)$. Smoking has been considered as harmful on the cardiovascular system through nicotine, and increased blood nicotine levels of smokeless tobacco consumers can increase the risk of cardiovascular diseases. Several studies have reported that using these products can increase the risk factors for fatal myocardial infarctions (21-24). Güven et al. (11) conducted a study on Maras powder consumers and found that serum lipid levels were high and that diastolic function parameters were impaired compared to the control group. They stated that Maras powder was as harmful to the cardiovascular system as smoking cigarettes. Similarly, Allen et al. (25) investigated the incidence of cardiovascular diseases in smokeless tobacco consumers (26). They observed that blood pressure, heart rate and functions, and lipoprotein levels were different from the control group. These values were increased or decreased among smokeless tobacco users, while they remained stable within the control group. In our study, we detected statistically and significantly increased ECG findings in participants regardless of their method of consuming tobacco. While there was no significant difference between only Maras powder group and only smoking group, the ECG findings of both smoking and Maras powder consuming group was found to be statistically and significantly higher than the control group. When age and gender of the participants were considered, other cardiac parameters such as blood pressure, heart rate and lipid levels were not different between groups. This indicates that tobacco use is a risk factor for cardiovascular diseases alone, but using Maras powder along with smoking increases that risk. Smokers are exposed to more than 3,000 substances, including alkaloids, as well as many toxic and carcinogenic substances through tobacco consumption. For smokers, exposure to carcinogenic substances may also happen by burning the cigarette and inhaling the smoke of it. Smoke from the cigarette causes chronic inflammation in the airways and is the underlying etiology of various diseases such as chronic bronchitis, COPD, oral and oropharyngeal cancers and lung cancers. Recently, it has been reported that free radicals increase in patients with COPD, which may be responsible for the disease $(27,28)$. Several studies have proved that the use of smokeless tobacco causes systemic effects by the association among usage of smokeless tobacco, free radicals, and endothelia $(19,21)$. Köksal et al. (8) investigated the effects of Maras powder on the airways and cardiovascular system. According to the results of the study, Maras powder had no effect on airways because it was not inhaled, although it did affect the cardiovascular system equivalent to smoking cigarettes. In another similar study, Büyükbese et al. (6) investigated the effects of Maras powder on pulmonary function and they observed that pulmonary function was negatively affected. In our study, we could not detect any difference in pulmonary function parameters between the smokers and the control group. This may be associated with the fact that we conducted our study in the rural regions of Turkey, which exposed patients to biomass in varying degrees. There was no statistically significant difference in pulmonary function parameters between the cases of Maras powder use and smoking cigarette use. This was associated with the fact that Maras powder did not circulate through the respiratory system like smoking cigarettes. Maras powder contains many harmful substances such as nicotine and this can affect hematological and biochemical parameters. In a research conducted by Ukoha et al. (29) in Wistar rats treated with smokeless tobacco, hematological and homeostatic effects of smokeless tobacco in sublethal doses were shown to increase leukocyte levels and decrease erythrocyte and platelets compared to the control rat group. They suggested that smokeless tobacco use in high doses and in chronic processes might be a risk factor for abnormal homeostatic and hematological conditions. Another clinical study by Kılınç et al. (12) found high leukocyte levels and low monocyte and thrombocyte levels in participants using Maras powder. It has been shown that Maras powder can adversely affect biochemical and hematologic parameters negatively. Many studies have found a positive correlation between Maras powder use, $\mathrm{Hb}$, leukocyte, lipid profiles, and C-reactive protein values. However, there are reports in the literature that suggest no statistical correlation (30). When comparing the participants 
of our study, leukocyte levels were found to be higher in the group using Maras powder compared to the smokers group. The leukocyte levels were also higher in the group using both Maras powder and smoking compared to the only smoking group. Further analyses suggested that increased $\mathrm{Hb}$ and lipid profiles were associated with age and gender. There was no difference between the groups in terms of other biochemical and hematological parameters. The obtained data support the opinion that Maras powder has systemic adverse effects and it may increase peripheral leukocyte levels. It is a well-known fact that differences in the pack-per-year consumption, the kind of tobacco, and depth and duration of inspiration of the smoke are important contributors to the adverse effects of smoking cigarettes. Frequency, using method, duration held in the mouth, oral flora, and amount of saliva are among other factors on the emergence of adverse effects of tobacco (31-34). There are studies available emphasizing that smokeless tobacco may cause disturbances in or around mouth. Also, it can cause oral-oropharyngeal cancers, leukoplakia, bleeding gums, and gum abnormalities (35-37). Considering leukoplakia, there are studies indicating that smokeless tobacco has a 3.0\% lower rate of progressing into dysplasia when compared to normal cigarette smoking. Therefore, progression into cancer is less and slower $(38,39)$. But, adverse effects of smokeless tobacco have varying degrees of risk depending on various conditions such as consumption route and frequency. In an analysis of case-control studies, risk for oral and respiratory cancers was found to be statistically and significantly higher in participants using dry snuff, lower in moist snuff and chewing tobacco (40). In our study, we found that effective parameters on developing oral lesions were the amount of daily use and method of use. We concluded that direct contact of Maras powder with mucosa increased the risk for oral lesions up to 8 times compared to using it wrapped in paper. Also, a positive correlation between daily use frequency and oral lesions was found. According to this, we can conclude that use of smokeless tobacco may contribute to deterioration of mucosal integrity, leukoplakia, and dysplasia. The progression of oral-oropharyngeal cancer development by consumption with direct contact to mucosa and number of daily use sessions is also a concern. This is consistent with results of many studies within the literature (35-37). But the fact that we did not obtain samples from lesions or mucosa of the participants to process histopathologically was a limiting factor of our study.

\section{CONCLUSION}

In conclusion, the smokeless tobacco use, which is considered as an alternative way of quitting smoking, does not have adverse effects on respiratory functions. However, it is an important risk factor for many life-threatening health conditions such as cardiac diseases, impairment of several blood parameters, oral lesions, and gum abnormalities that contribute to malignancies. Also, daily use frequency and method of use (direct contact to mucosa) for these tobacco products should be considered due to their harmful effects. Social awareness should be created for smokeless tobacco use, similar to smoking, in order to fight this habitual threat to public health. Additionally, more comprehensive studies are necessary to raise awareness about the effects of smokeless tobacco as a serious health problem.

\section{Ethics}

Ethics Committee Approval: The study was approved Department of Pulmonary Medicineat Dr. Sureyya Adanalı Göksun State Hospital and Kahramanmaraş Sütçü Imam University Faculty of Medicine by the Local Ethical Committee and was in accordance to the Declaration of Helsinki (24.11.2014/181).

Informed Consent: There is not informed consent because of nature of the retrospective study.

Peer-review: External and internal peer-reviewed.

\section{Authorship Contributions}

Concept: I.I., H.A., Design: I.I., H.A., Data Collection or Processing: U.S.K., P.A.G., Analysis or Interpretation: I.I., N.A., Literature Search: I.I., M.T., Writing: I.I.

Conflict of Interest: No conflict of interest was declared by the authors.

Financial Disclosure: The authors declared that this study received no financial support.

\section{REFERENCES}

1. Ashley DL, Burns D, Djordjevic M, Dybing E, Gray N, Hammond SK, et al; WHO Study Group on Tobacco Product Regulation. The scientific basis of tobacco product regulation. World Health Organ Tech Rep Ser 2008;1-277, 1 p following 277.

2. Örsel 0. Dünyada kullanılan tütün çesitleri. www.toraks.org.tr/sub/sigarasiz/ DunyadaKullanilanTutunUrunleriosman orsel.pdf. Son erisim 07.12.2009.

3. Kafas A: Analysis of factors affecting cigarete smoking and Maras powder use among adults in the urban area of Kahramanmaras. Master's Thesis, Institute of Science, Department of Agricultural Economics, Kahramanmaras Sutcu Imam University, Turkey, 2011, https://tez.yok.gov.tr/UlusalTezMerkezi/ SearchTez

4. Sucaklı MH, Kahraman H, Çelik M, Keten HS. An Evaluation of Knowledge, Attitudes and Behavior regarding Smoking and Smokeless Tobacco (Maras Powder) Use among High School Children. Gaziantep Med J 2015;21:225-32.

5. Erenmemisoğlu A, Tekol Y, Kartal M, Kurucu S. The use of smokeless tobacco in our country "Maras Powder". Turk J Med Sci 1992;16:567-76. 
6. Büyükbese MA, Köksal N, Güven A, Çetinkaya A. Effects of smokeless tobacco "Maras Powder" use on respiratory function. Tohoku J Exp Med 2004;204:173-8.

7. Ozkul Y, Donmez H, Erenmemisoglu A, Demirtas H, Imamoglu N. Induction of micronuclei by smokeless tobacco on buccal mucosa cells of habitual users. Mutagenesis 1997;12:285-7.

8. Köksal N, Güven A, Çetinkaya A. Büyükbese MA. Dumansız Tütün "Maras Otu" Kullanımının Solunum Fonksiyonları Üzerine Olan Etkileri. Akciger Arsivi 2004;5:174-8.

9. Kiowski W, Linder L, Stoschitzky K, Pfisterer M, Burckhardt D, Burkart F, et al. Diminished vascular response to inhibition of endothelium-derived nitric oxide and enhanced vasoconstriction to exogenously administered endothelin-1 in clinically healthy smokers. Circulation 1994;90:27-34.

10. Powell JT, Higman DJ. Smoking, nitric oxide and the endothelium. Br J Surg 1994;81:785-7.

11. Güven A, Köksal N, Büyükbese MA, Çetinkaya A, Sökmen G, Aksu E, et al. Effects of Using a Different Kind of Smokeless Tobacco on Cardiac Parameters: "Maras powder". Anadolu Kardiyoloji Dergisi 2003;3:230-5.

12. Kılınç M, Okur E, Yıldırım I, Inanç F, Kurutas EB. The Investigation of the Effect of Maras Powder (Smokeless Tobacco) on Hematological Parameters. Turk J Haematol 2004;21:131-6.

13. Goo MJ. Smokeless Tobacco. The Health Conseoquences of Snuff and Chewing Tobacco. Nurse Practitioner 1992;17:24-36.

14. Rodu B. An Alternatine Approach to Smoking Control. Am J Med Sci 1994;308:32-4.

15. Castiglia PT. Smokeless Tobacco. J Pediatr Health Care 1994;8:274-6.

16. Cok I, Oztürk R. Smokeless Tobacco Usage in the World and Turkey. Journal of Faculty of Pharmacy of Gazi University 1996;13:105-10.

17. Saıtoh F, Noma M, Kawashıma N. The Alcaloid Contents of Sixty Nicotiana Species. Phytochemistry 1985;24:477-480.

18. Benowitz NL. Pharmacological aspects of cigarette smoking and nicotine addiction. N Engl J Med 1998;319:1318-30.

19. Mitchell BE, Sobel HL, Alexander MH. The adverse health effects of tobacco and tobacco related products. Prim Care 1999;26:463-98

20. Bartal M. Health effects of tobacco use and exposure. Monaldi Arch Chest Dis 2001;56:545-54

21. Traber MG, van der Vliet A, Reznick AZ, Cross CE. Tobacco-related diseases. Is there a role for antioxidant micronutrient supplementation? Clin Chest Med 2000;21:173-87.

22. Russell MA, Jarvis MJ, Devitt G, Feyerabend C. Nicotine intake by snuff users, Br Med J (Clin Res Ed) 1981;283:814-7.

23. Lee PN. Circulatory disease and smokeless tobacco in Western populations: a review of the evidence. Int J Epidemiol 2007;36:789-804.
24. Boffetta P, Straif K. Use of smokeless tobacco and risk of myocardial infarction and stroke: systematic review with metaanalysis. BM] 2009;18:b3060.

25. Allen SS, Hatsukami D, Jensen J, Grillo M, Bliss R. Effects of Treatment on Cardiovascular Risk Among Smokeless Tobacco Users. Preventive Medicine 2002;6:242-5

26. Tabak L. Is smokeless tobacco less harmful than smoking? Anadolu Kardiyol Derg 2003;3:236-7.

27. Kharitonov SA, Barnes PJ. Biomarkers of some pulmonary diseases in exhaled breath. Biomarkers 2002;7:1-32.

28. Couillard A, Koechlin C, Cristol JP, Varray A, Prefaut C. Evidence of local exercise-induced systemic oxidative stress in chronic obstructive pulmonary disease patients. Eur Respir J 2002;20:1123-9.

29. Ukoha UU, Dimkpa U, Maduka SO. "The effect of sub-lethal doses of smokeless tobacco (snuff) on certain hematological and hemostatic parameters in Wistar rats." Journal of Experimental and Integrative Medicine 2012;225-30.

30. Asplund K, Nasic S, Janlert U, Stegmayr B. Smokeless tobacco as a possible risk factor for stroke in men: a nested case-control study. Stroke 2003;34:1754-9.

31. Hatsukami DK, Lemmonds C, Tomar SL. Smokeless Tobacco Use: Harm Reduction or Induction Approach. Preventive Medicine 2004;38:309-17.

32. Rodu B, Jansson C. Smokeless Tobacco and Oral Cancer: A Review of the Risks and Determinants. Critical Reviewvs in Oral Biology and Medicine 2004;21:156-7.

33. Boyle P, Macfarlane GJ, Maisonneuve P, Zheng T, Scully C, Tedesco B. Epidemiology of mouth cancer in 1989: a review. J R Soc Med 1990;83:72430.

34. Scully C. Oncogenes, tumor suppressors and viruses in oral squamous cell carcinoma. J Oral Pathol Med 1993;22:337-47.

35. Fant RV, Henningfield JE, Nelson RA, Pickworth WB. Pharmacokinetics and Pharmacodynamics of Moist Snuff in Humans. Tob Control 1999;8:387-92.

36. Walsh PM, Epstein JB. The Oral Effects of Smokeless Tobacco. J Can Dent Assoc 2000;66:22-5.

37. Hatsukami DK, Lemmonds C, Tomar SL. Smokeless Tobacco Use: Harm Reduction or Induction Approach. Prev Med 2004;38:309-17.

38. Greer RO, Poulson TC, Boone ME, Lindenmuth JE, Crosby L. Smokeless tobacco associated oral changes in juvenile, adult and geriatic patients: Clinical and histomorphologic features. Gerodontics 1986;2:87-98.

39. Axell T, Mornstad H, Sundstrom B. The relation of the clinical picture to the histopathology of snuff dipper's lesions in a Swedish population. J Oral Pathol 1976;5:229-36.

40. Rodu B, Cole P. Smokeless tobacco use and cancer of the upper respiratory tract. Oral Surg Oral Med Oral Pathol Oral Radiol Endod 2002;93:511-5. 